\title{
Planejamento e controle integrado entre segurança e produção em processos críticos na construção civil
}

\author{
Fabrício Borges Cambraia UFRGS \\ Tarcísio Abreu Saurin UFRGS \\ Carlos Torres Formoso UFRGS
}

\section{RESUMO}

O planejamento e controle da segurança são reconhecidos como medida eficaz na prevenção de acidentes do trabalho, sobretudo em processos com elevado risco de acidentes, os quais são aqui denominados de processos críticos. Este artigo propõe um método para planejamento de processos críticos na construção civil e descreve uma aplicação prática de princípios para projeto de processos seguros. Foi realizado o planejamento integrado entre segurança e produção para a montagem de uma escada pré-fabricada de concreto, atividade definida como processo crítico na construção de um hospital. $\mathrm{O}$ estudo indicou que o planejamento de processos críticos deve ser desenvolvido em três etapas: coleta de informações e tomada de decisões iniciais; preparação e difusão dos planos; e ajustes nos planos após o primeiro ciclo de produção. Os resultados demonstram como os planos de segurança contribuem para delimitar zonas de trabalho seguras e inseguras, bem como tornar visíveis os limites entre essas zonas.

\section{Integrated safety and production planning of critical processes in construction}

\begin{abstract}
Integrated safety and production planning is known as one of the most effective preventive measures to tackle accidents. It is even more important in highrisk construction processes, referred to as critical processes in this paper. A method to plan critical processes in construction is presented in this study. The method was tested in the installation of a pre-fabricated staircase, which was considered to be a critical process in the construction of a hospital. The proposed method has three stages: data collection on process and product characteristics; development and dissemination of plans; adjustments in the plans after the first cycle of execution. The results point out how safety planning and control contribute to establish safe and unsafe working zones as well as how it makes visible the boundaries between those zones.
\end{abstract}

\section{KEY WORDS}

Safety management, production planning and control, critical processes, risk management. 


\section{INTRODUÇÃO}

As conseqüências da falta de segurança nos canteiros de obra, visíveis através das perdas de ordem humana, econômica ou social, têm estimulado a busca por melhorias no desempenho da segurança na construção. De acordo com Suraji et al. (2001), muitas dessas perdas têm sua origem na ausência ou em deficiências do processo de planejamento e controle da segurança. Por esta razão, este processo vem sendo objeto de estudo de vários autores (KARTAM, 1997; TRANI; LATICINA, 2002; HINZE, 1998; SAURIN et al., 2004). Além disso, o planejamento e controle da segurança é requisito obrigatório de normas opcionais e obrigatórias de segurança, sendo também uma prática comumente empregada por empresas líderes em gestão de segurança (HINZE, 2002; SAURIN, 2002).

\section{E ste artigo consiste em propor um método para 0 planejamento detalhado de processos críticos, 0 qual inclui a definição de zonas de trabalho seguras e inseguras, bem como seus limites. Para tanto, foi realizado um estudo empírico no planejamento do processo de execução de uma escada pré-fabricada}

\section{em uma obra de construção de um hospital.}

Diversos estudos indicam que se pode aumentar a eficiência e eficácia dos planos de segurança através da integração do planejamento da segurança e da produção (CIRIBINI; RIGAMONTI, 1999; KARTAM, 1997; TRANI; LATICINA, 2002; HINZE, 1998; SAURIN et al., 2004). Entretanto, a maioria dos estudos realizados adota uma visão muito restrita de planejamento e controle da segurança. Ciribini e Rigamonti (1999), Kartam (1997) e Trani e Lanticina (2003), por exemplo, focam-se, principalmente, na integração da segurança às técnicas para geração, como o CPM ou a linha de balanço. Saurin et al. (2004), por sua vez, propuseram um modelo de planejamento e controle integrado da segurança e produção (Modelo de PCS), no qual se buscou integrar de forma mais ampla a gestão da segurança ao planejamento e controle da produção, considerando-se conceitos e práticas de gestão da produção adotados com sucesso na indústria da construção e em outros setores.

O Modelo de PCS está baseado, principalmente, no conceito de planejamento e controle proposto por Laufer e Tucker $(1987 ; 1988)$ e nos trabalhos de Ballard e Howell (1997) e Ballard (2000), que desenvolveram o Sistema Last Planner de Controle da Produção. Conforme Laufer e Tucker (1987; 1988), o processo de planejamento e controle da produção é entendido como um processo gerencial composto por cinco etapas (preparação do processo de planejamento, coleta de dados, elaboração de planos, difusão de informações, implementação dos planos e avaliação do processo de planejamento). O modelo de PCS, inicialmente desenvolvido por Saurin (2002) em obras industriais, foi aperfeiçoado no estudo de Cambraia (2004), a partir de sua aplicação na obra de construção de um hospital.

O estudo de Saurin (2002) indicou que a definição do método de execução do processo, isto é, a maneira como o grupo de trabalhadores vai realizar o trabalho, constitui uma atividade crítica para o sucesso do planejamento da segurança. O planejamento dos métodos de execução também vem sendo enfatizado por normas e legislações. Por exemplo, a Diretiva Européia 92/57/CEE (Prescrições Mínimas de Segurança e de Saúde a Aplicar nos Canteiros Temporários ou Móveis) exige coordenadores de segurança durante as fases de projeto e produção de uma obra, sendo uma de suas principais atribuições a garantia da segurança durante a execução de todos os processos construtivos por intermédio de planejamento (DIAS; FONSECA, 1996).

Além disso, o esforço de planejamento dos métodos parte do pressuposto de que deve ser minimizada a necessidade de tomada de decisões no momento da execução pelos trabalhadores, como, por exemplo, a definição da seqüência de execução e das medidas preventivas necessárias, assim como onde as mesmas devem ser implantadas no canteiro. Desta forma, pretende-se reduzir a probabilidade de os trabalhadores se depararem com condições novas e imprevistas, visto que nessas condições a chance de erro aumenta muito (RASMUSSEN et al., 1994; REASON, 1997).

No estudo para aperfeiçoamento do Modelo de PCS, Cambraia (2004) identificou que, além de não serem documentadas, muitas das decisões tomadas nas reuniões de planejamento não eram suficientemente detalhadas. A falta de detalhamento contribuía para o aumento de situações que requeriam improvisações por parte dos trabalhadores. Isso ocorria principalmente pelo fato de que, na prática, era inviável detalhar e discutir em profundidade, para todos os processos, as várias alternativas existentes para o método executivo. Contudo, como estratégia para minimizar esse problema, é possível priorizar determinados processos, em 
função das necessidades de produção e segurança, justificando uma maior formalização das decisões em planos específicos para os processos executivos considerados críticos.

Este artigo consiste em propor um método para o planejamento detalhado de processos críticos, o qual inclui a definição de zonas de trabalho seguras e inseguras, bem como seus limites. Para tanto, foi realizado um estudo empírico no planejamento do processo de execução de uma escada préfabricada em uma obra de construção de um hospital. Através do planejamento realizado, buscou-se, principalmente, minimizar erros humanos através do projeto do trabalho, utilizando como principal referencial teórico o modelo dinâmico para a gestão da segurança, proposto por Rasmussen et al. (1994) e Rasmussen (1997), descrito a seguir.

\section{MODELO DINÂMICO PARA A GESTÃO DA SEGURANÇA}

Rasmussen et al. (1994) propõem um modelo para explicar o comportamento organizacional em ambientes dinâ- micos e complexos, representado na Figura 1. Este modelo explica os mecanismos que influenciam o comportamento das pessoas nesses contextos. Conforme Rasmussen (1997), em qualquer sistema de trabalho é possível identificar um espaço no qual o homem pode tomar decisões livremente, que é delimitado por três fronteiras: (a) o limite do comportamento funcionalmente aceitável; (b) a fronteira além da qual o desempenho é ineficiente em um ambiente competitivo (limite da falência econômica); e (c) a fronteira além da qual a carga de trabalho é muito alta (limite da carga de trabalho inaceitável).

A transposição do limite do comportamento funcionalmente aceitável representa o acidente, interpretado por Rasmussen et al. (1994) como uma perda de controle dos processos físicos. Visando a evitar a perda de controle e, principalmente, reconhecendo o fato dos erros serem inevitáveis, Rasmussen et al. (1994) enfatizam a necessidade de projetar processos que tornem visíveis os limites do trabalho seguro e garantam uma tolerância à ocorrência de erros, como, por exemplo, projetando-se proteções físicas para os mesmos.

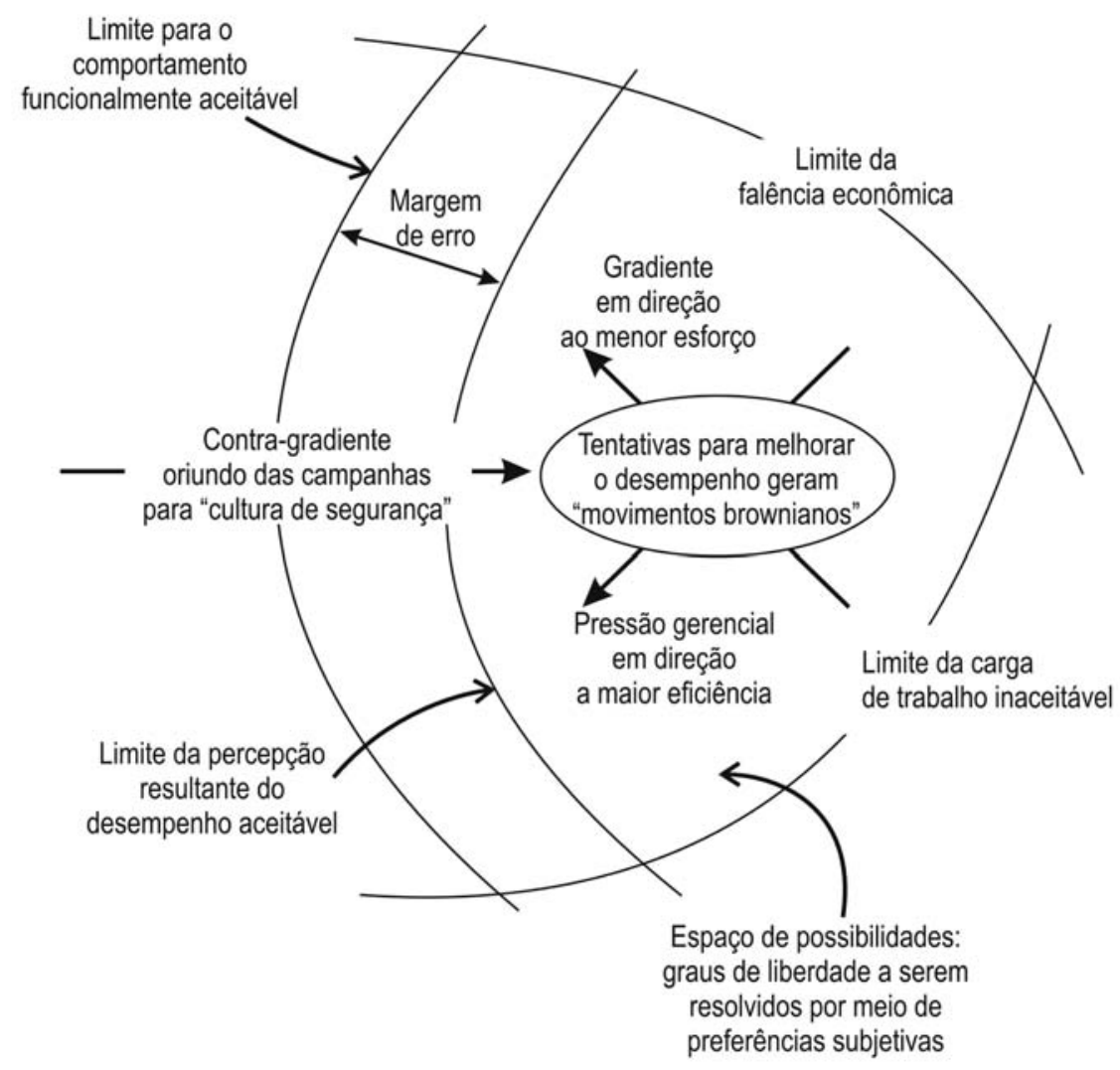

Figura 1: Modelo dinâmico de gestão da segurança (RASMUSSEN, 1997). 
Rasmussen et al. (1994) salientam que, com a experiência no trabalho, há uma busca constante do indivíduo em prol de menor esforço na realização das tarefas, como também uma busca contínua por maior eficiência por parte dos gestores. Essas tentativas significam uma adaptação ao trabalho ou ao processo, sendo que o resultado dessa adaptação em geral resulta em menor esforço e em uma maior eficiência, implicando em uma migração sistemática para o limite do comportamento funcionalmente aceitável. No entanto, essa migração deve ser contida por um contra-gradiente de segurança, o qual pode ser desenvolvido por meio de campanhas para promoção da segurança (RASMUSSEN, 1997). As campanhas de segurança têm como função básica fazer com que as pessoas tenham uma percepção do limite do comportamento funcionalmente aceitável aquém do real, de forma a garantir uma margem para o erro. Essa percepção abaixo do real é representada no modelo de Rasmussen (1997) pelo limite da percepção resultante do desempenho aceitável.

Howell et al. (2002) propõem o uso desse modelo para a gestão da segurança na construção civil, bem como uma adaptação das fronteiras definidas por Rasmussen (1997), dividindo o ambiente de trabalho em três zonas, conforme ilustra a Figura 2. Em cada zona, Howell et al. (2002) propõem estratégias de gestão específicas, listadas a seguir:

(a) Zona de segurança: deve-se ampliar esse espaço, por intermédio, por exemplo, do planejamento dos processos. Howell et al. (2002) sugerem que a zona de segurança pode ser expandida empregando-se first run studies. De acordo com Ballard (2000), first run studies é uma forma de planejamento de processos, similar à prototipagem, que deve contar com a participação de representantes dos profissionais envolvidos. O processo em estudo deve ser examinado em detalhes, buscando-se idéias e sugestões de todas as partes envolvidas. Após um pequeno número de ciclos de execução, devem-se realizar os ajustes necessários para melhoria dos processos;

(b)Zona de perigo (trabalho no limite): deve-se dar visibilidade ao limite além do qual o trabalho não pode mais ser considerado seguro e capacitar as pessoas quanto ao reconhecimento desse limite. Para isso, por exemplo, podem ser projetados dispositivos de segurança à prova de erros humanos, como os poka-yokes;

(c) Zona de perda de controle (além do limite): projetar maneiras de limitar as conseqüências do perigo quando o controle for perdido.

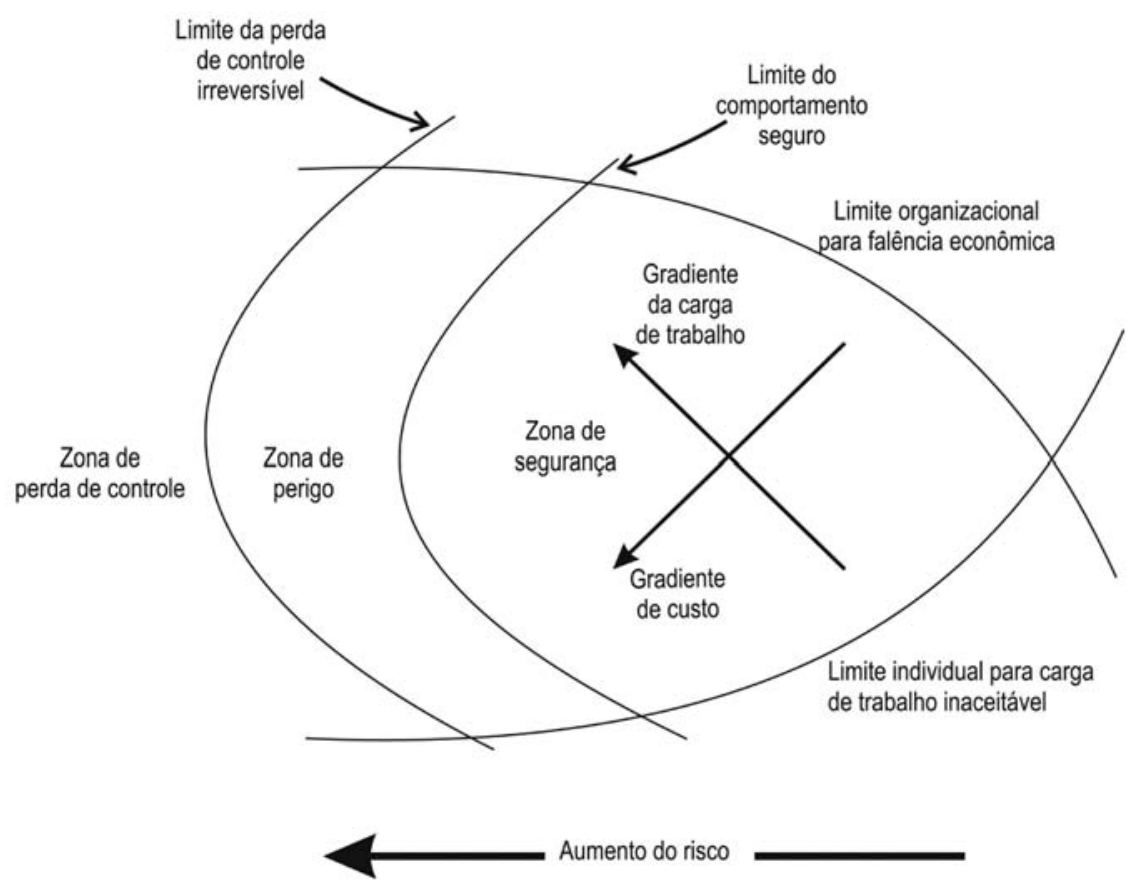

Figura 2: Divisão em zonas de trabalho proposta por Howell et al. (2002) a partir das fronteiras por Rasmussen (1997). 


\section{MÉTODO DE PESQUISA}

O estudo de caso foi realizado em uma obra de construção de dois prédios hospitalares, um estacionamento de veículos e um centro clínico, localizada em Porto Alegre - RS. Esta obra teve duração de 18 meses e foi realizada através de um consórcio firmado entre duas empresas construtoras, tendo no seu pico cerca de 300 trabalhadores (cerca de 95\% destes de empresas subcontratadas). Uma das empresas construtoras havia participado de estudos anteriores de implementação do modelo de PCS (SAURIN, 2002; SAURIN et al., 2004). Essa empresa caracteriza-se por executar obras nas quais, em geral, os clientes são muito exigentes em relação à segurança. Entretanto, ao contrário dos estudos anteriores, neste empreendimento o contratante não apresentou exigências adicionais de gestão da segurança além do atendimento das normas obrigatórias, cuja responsabilidade era das empresas contratadas.

A estratégia de pesquisa adotada foi a pesquisa-ação, sendo o estudo empírico realizado ao longo dos meses de setembro e outubro de 2003. O estudo contou com a participação de seis profissionais: um representante do fornecedor da escada pré-moldada, o qual foi também o responsável pela montagem; dois engenheiros (de planejamento e de contratos) da empresa construtora; o técnico de segurança residente no canteiro; um estagiário de engenharia civil e o primeiro autor deste artigo. Cabe destacar que o primeiro autor participou ativamente de todo o desenvolvimento do estudo (desde a definição do processo crítico até a etapa de ajustes nos planos após a primeira rodada de montagens).
Ao longo do estudo foram realizadas seis reuniões, as quais têm seus objetivos, participantes e seu tempo de duração apresentados, em ordem cronológica, na Figura 3. Na reunião inicial, o primeiro autor apresentou algumas diretrizes, baseadas na revisão de literatura, para embasar a definição dos processos críticos, as quais foram usadas conjuntamente com a avaliação das prioridades em termos de planejamento da produção. Uma vez definido o

\section{planejamento para a montagem da escada foi estruturado em três fases: (a) coleta de informações e decisões preliminares; (b) preparação e difusão dos planos e; (c) ajustes nos planos após a rodada inicial de implementação.}

processo de montagem da escada como o processo crítico a ser investigado, na reunião seguinte o fornecedor da escada apresentou seu projeto, incluindo alguns detalhes da execução. As duas reuniões seguintes foram destinadas à elaboração dos planos de segurança. Além das reuniões, aconteceu uma intensa troca de e-mails entre os três envolvidos nessa etapa (engenheiro de planejamento, estagiário de engenharia e primeiro autor).

A quinta reunião aconteceu um dia antes do início do primeiro ciclo de montagem. Nesse momento, os planos foram apresentados a todos os envolvidos e, após isso, foram definidos os responsáveis pela execução das proteções e treinamentos. Todo o primeiro ciclo de montagem foi acompanhado pelo engenheiro de planejamento, estagiário, técnico

\begin{tabular}{|c|c|c|c|}
\hline Objetivos & $\begin{array}{l}\text { Número da } \\
\text { reunião }\end{array}$ & Participantes & $\begin{array}{c}\text { Duração } \\
\text { aproximada }\end{array}$ \\
\hline Definição dos processos críticos & 01 & $\begin{array}{l}\text { Engenheiros de contratos e de } \\
\text { planejamento e o primeiro autor }\end{array}$ & 1:00 h \\
\hline Entender o processo e os detalhes da execução & 02 & Todos os participantes & $2: 00 \mathrm{~h}$ \\
\hline $\begin{array}{l}\text { Discussão sobre os planos desenvolvidos } \\
\text { para a montagem da escada }\end{array}$ & 03 e 04 & $\begin{array}{l}\text { Engenheiro de planejamento, } \\
\text { estagiário e o primeiro autor }\end{array}$ & $1: 30 \mathrm{~h}$ \\
\hline $\begin{array}{l}\text { Consenso dos planos e definição dos últimos } \\
\text { detalhes antes da primeira rodada de montagens }\end{array}$ & 05 & $\begin{array}{l}\text { Todos, exceto o representante } \\
\text { do fornecedor }\end{array}$ & $1: 30 \mathrm{~h}$ \\
\hline $\begin{array}{l}\text { Discutir os ajustes necessários após a } \\
\text { primeira rodada de montagens }\end{array}$ & 06 & $\begin{array}{c}\text { Engenheiros de planejamento e } \\
\text { contratos, estagiário e primeiro autor }\end{array}$ & $1: 00 \mathrm{~h}$ \\
\hline
\end{tabular}

Figura 3: Detalhes das reuniões realizadas ao longo do estudo de caso. 
de segurança e o primeiro autor. Alguns detalhes dessas montagens foram fotografados, os quais, além das percepções dos participantes, serviram de apoio para a realização de ajustes nos planos para as rodadas subseqüentes. Esses ajustes foram discutidos na última reunião do estudo.

\section{OS CRITÉRIOS UTILIZADOS PARA A ESCOLHA DO PROCESSO CRÍTICO}

Os processos críticos foram definidos com base nos trabalhos de Dias e Fonseca (1996) e de Costella (1999), assim como em requisitos do planejamento do canteiro da obra investigada. Dias e Fonseca (1996) apresentam uma lista com 10 categorias de processos (Figura 4) que necessitam de cuidados especiais na gestão da segurança e saúde do trabalhador, os quais são apontados pela Diretiva Européia (92/57/CEE). A existência de processos que contenham esses perigos em um determinado canteiro, segundo a mesma diretiva, requer atenção especial através da intervenção de coordenadores de segurança e do desenvolvimento de planos de segurança específicos.

Dos processos a serem executados no período do estudo, dois se enquadravam nas categorias da Diretiva. Foram identificados aqueles que apresentavam exposição dos trabalhadores a perigos de queda de altura e também os que envolviam a montagem e desmontagem de elementos préfabricados, conforme destaque na Figura 4. Diante disto, foram considerados prioritários os processos de montagem da escada e dos painéis de fachada pré-fabricados.
Os dados de Costella (1999) reforçam a necessidade de ênfase nos processos priorizados em função do grau de perigos. O estudo desse autor analisou cerca de 3.000 acidentes do trabalho ocorridos entre 1997 e 1998, no Estado do Rio Grande do Sul, apontando as principais causas dos acidentes, bem como classificações dos mesmos segundo a natureza e agente causador. Por exemplo, três das principais categorias de natureza dos acidentes (impacto sofrido, queda com diferença de nível e esforços excessivos ou inadequados), que representaram 63\% dos acidentes notificados (COSTELLA, 1999), estão diretamente relacionadas com os perigos verificados no processo de montagem da escada e dos painéis de fachada.

Entre os dois processos priorizados, foi necessário escolher um para o estudo. Foi escolhida a montagem da escada em função de dois motivos. O primeiro relaciona-se com a criação de acessos verticais na obra, o que, com a montagem da escada, eliminaria a necessidade de execução de escadas provisórias. O segundo diz respeito ao curto prazo de execução da escada, o que possibilitou um acompanhamento mais detalhado e completo do processo por parte dos pesquisadores.

\section{O PROCESSO DE PLANEJAMENTO PARA A MONTAGEM DA ESCADA PRÉ-FABRICADA}

O planejamento para a montagem da escada foi estruturado em três fases: (a) coleta de informações e decisões preliminares; (b) preparação e difusão dos planos e; (c) ajustes

\begin{tabular}{cl}
\hline 01 & $\begin{array}{l}\text { Processos que exponham os trabalhadores a riscos de soterramento, de afundamento ou de queda em altura, particularmente } \\
\text { agravados pela natureza da atividade, do meio envolvente do posto de trabalho ou do canteiro }\end{array}$ \\
\hline 02 & $\begin{array}{l}\text { Processos que exponham os trabalhadores a substâncias químicas ou biológicas que representem riscos específicos para } \\
\text { segurança e saúde }\end{array}$ \\
03 & Processos com radiações ionizantes, em relação aos quais seja obrigatória a designação de zonas controladas ou vigiadas \\
04 & Processos a serem executados na proximidade de linhas elétricas de alta tensão \\
05 & Processos que impliquem em riscos de afogamento \\
06 & Processos em poços, túneis ou galerias \\
07 & Processos de mergulho com aparelhagem \\
08 & Processos com utilização de ar comprimido (por exemplo: tubulões) \\
09 & Processos que impliquem a utilização de explosivos \\
\hline 10 & Processos de montagem e desmontagem de elementos pré-fabricados ou outros, cuja forma, dimensão ou peso exponham os \\
\hline
\end{tabular}

Figura 4: Processos que necessitam cuidados especiais na gestão da segurança e saúde do trabalhador (DIAS; FONSECA, 1996). 
nos planos após a rodada inicial de implementação. Cada uma dessas fases é discutida nos itens abaixo.

\subsection{Coleta de informações e decisões preliminares}

O primeiro passo no planejamento para montagem da escada foi a realização de uma reunião (reunião 02 indicada na Figura 3), em que se buscou coletar informações básicas a respeito do processo, tais como o peso das peças e as principais operações da montagem. Essa reunião foi dividida em duas partes. Na primeira parte, o fornecedor apresentou o projeto da escada e alguns detalhes sobre o procedimento de montagem. A escada pré-fabricada foi montada nos 10 pavimentos do edifício de estacionamento de veículos, sendo constituída por três lances, tendo o primeiro e o terceiro um peso de $1550 \mathrm{~kg}$ e o intermediário de $200 \mathrm{~kg}$.

Na segunda parte, os participantes da reunião visitaram o local de montagem com o intuito de esclarecer eventuais dúvidas a respeito do projeto e da execução. Nesta oportunidade, foi identificado que a viga intermediária, na qual se apoiavam os patamares da escada, ainda não havia sido executada em nenhum andar. Então, ocorreram discussões acerca da melhor alternativa para construção dessa viga. Inicialmente, estudou-se a possibilidade de executá-la em estrutura metálica. Entretanto, como se tratava de uma escada corta-fogo, esta alternativa foi descartada, decidindo-se pela execução em concreto armado moldado in loco.

As informações acerca do peso das peças foram importantes para a escolha do equipamento de transporte a ser utilizado na montagem, uma vez que era necessário verificar a capacidade de carga do mesmo. Neste processo, o equipamento utilizado foi a grua, cuja torre era fixa e posicionada entre os dois prédios. Além disso, foram discutidas possíveis interferências das condições climáticas, em especial a ação do vento. Uma das decisões tomadas foi que, em caso de chuva ou vento forte, o processo não poderia ser realizado, ainda que existissem pressões quanto ao prazo.

Considerando que quanto mais uma peça pesada é manipulada, maior é a probabilidade de ocorrência de acidentes (MACCOLLUM, 1995), procurou-se discutir com o fornecedor o posicionamento das peças no caminhão, para que as mesmas fossem colocadas na seqüência de montagem. Similarmente, também foi discutida a programação de entrega, de forma a não haver peças estocadas na obra. Neste sentido, o fornecedor informou que seria utilizado um caminhão dotado de guindaste articulado hidráulico, sendo que o mesmo tinha capacidade de transportar 8 peças de $1550 \mathrm{~kg}$ (4 do $1^{\circ}$ e 4 do $3^{\circ}$ lance) e 4 peças de $200 \mathrm{~kg}$, do lance intermediário. Essa quantidade permitia a montagem das escadas de $4 \mathrm{pa}-$ vimentos. O tempo de montagem estimado foi, em média, de 40 minutos por peça. Com esta estimativa, a montagem das peças trazidas por um caminhão poderia ser realizada em um dia, pois totalizava 8 horas de trabalho. Diante disto, o fornecedor afirmou que não havia necessidade de estoque na obra.

Apesar da preocupação em manusear as peças o mínimo possível, o fornecedor explicou que havia necessidade de tombamento das peças na calçada, ao serem retiradas do caminhão. Essa necessidade foi justificada em função da impossibilidade das peças serem transportadas deitadas, pelo risco de trincas. Assim, elas seriam retiradas do caminhão, colocadas na calçada e tombadas, para que, então, pudessem ser içadas pela grua. Para o tombamento, foram identificadas duas opções visando a minimizar o risco de danos nas peças: tombá-las sobre uma caixa de areia ou sobre um cavalete de madeira. Optou-se pelo cavalete, principalmente pelo fato de o fornecedor se comprometer em desenvolver o mesmo, entregando-o durante o primeiro ciclo de montagens. A Figura 5 apresenta um detalhe do cavalete de madeira, bem como ilustra a posição em que as peças foram transportadas.

Além disto, o fornecedor apontou a necessidade do desenvolvimento de um dispositivo metálico que proporcionasse uma distribuição homogênea do peso das peças pré-moldadas sem perigo de trincas durante o içamento. $\mathrm{O}$ fornecedor ficou com a responsabilidade de projetar esse dispositivo e decidir o comprimento e tensão dos cabos de aço de ligação entre a peça pré-fabricada e o dispositivo metálico. A Figura 6 mostra o dispositivo metálico sendo utilizado durante o içamento de uma peça.

\subsection{Preparação e difusão dos planos}

Com as informações coletadas e as primeiras decisões tomadas, foram desenvolvidos dois planos de proteções coletivas para a montagem da escada pré-fabricada. Os dois planos foram preparados e difundidos entre os envolvidos na montagem através de reuniões, trocas de e-mails e treinamentos. $\mathrm{O}$ primeiro plano diz respeito às proteções coletivas necessárias e aos locais de implantação das mesmas em nível de canteiro de obras. O segundo refere-se às proteções específicas do posto de trabalho onde seriam posicionadas as peças. Cabe destacar que esta fase não é rigidamente separada da fase anterior, na qual os planos já estavam sendo preparados, embora não formalmente.

A Figura 7 apresenta o plano das proteções do canteiro, salientando-se as proteções periféricas em torno do poço da escada no último pavimento executado e o isolamento da área onde seriam tombadas as peças pré-fabricadas. Além disto, esse plano também estabelece que o caminhão deve ser estacionado na direção do poço da escada para minimizar 
o tempo de transporte pela grua, reduzindo, conseqüentemente, o tempo de exposição ao perigo durante o içamento das peças. $\mathrm{O}$ isolamento da parte inferior do poço foi outra proteção coletiva planejada.

Especificamente em relação aos locais de montagem, procurou-se visualizar os possíveis locais de posicionamento dos montadores durante a montagem de cada lance, tendo em vista a definição dos locais onde seriam colocados os cabos guias para a fixação dos cintos de segurança. Além disto, foram definidas as proteções periféricas (guarda-corpo com tela) e realizada uma avaliação acerca da necessidade ou não de assoalhamento das aberturas do piso. A Figura 8 apresenta

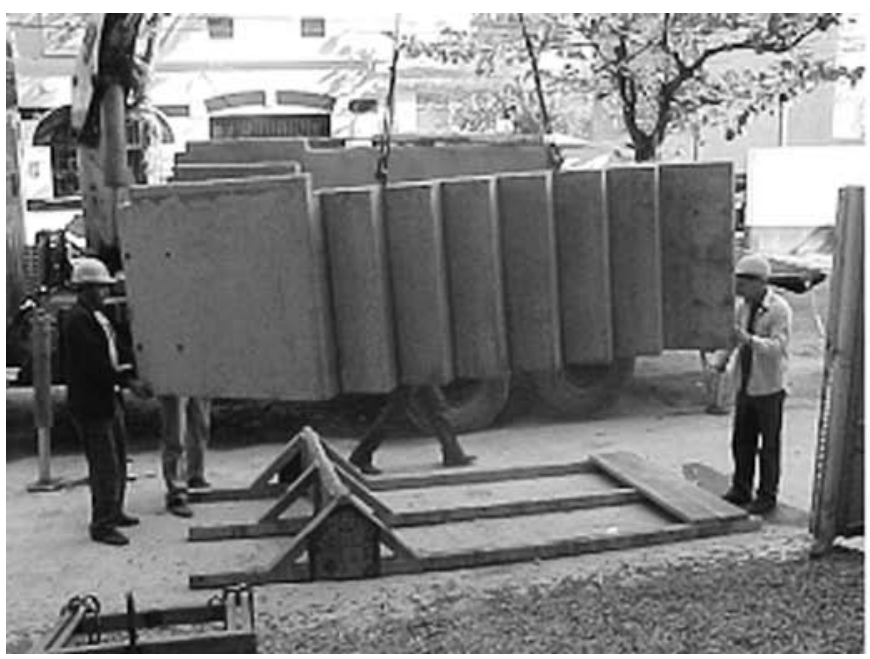

Figura 5: Cavalete de madeira usado para apoiar os lances da escada antes do içamento.

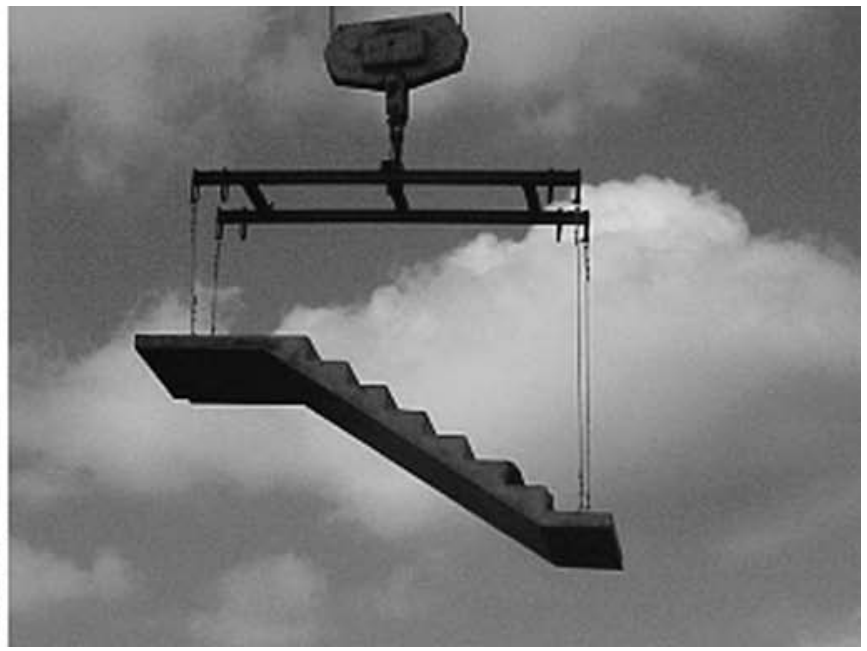

Figura 6: Dispositivo metálico usado durante o içamento das peças pré-fabricadas.

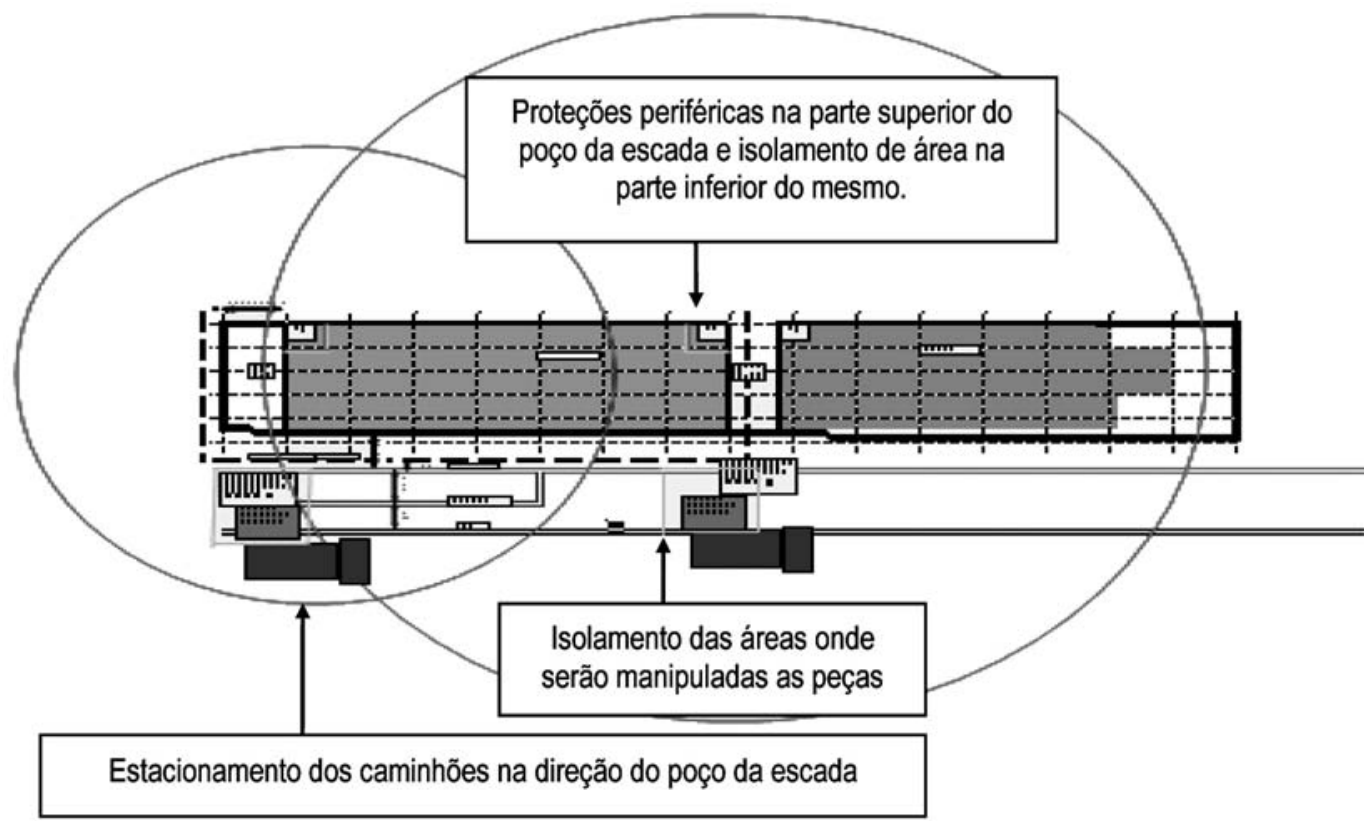

Figura 7: Plano de proteções coletivas em nível do canteiro de obras. 
as proteções adotadas no posto de trabalho, destacando-se o cinto de segurança projetado para o montador 1, o qual limitava sua movimentação para a frente. Além disso, optou-se por não assoalhar as aberturas, uma vez que o posicionamento dos guarda-corpos impedia o acesso às aberturas. Para o montador 2 não foi necessário cinto de segurança, pois o mesmo ficaria posicionado atrás da viga intermediária, a qual funcionaria como guarda-corpo.

Além dos planos de proteção coletiva, foi desenvolvido ainda um plano específico para treinamento dos envolvidos no processo de montagem. A orientação buscou enfatizar a importância de ajuda mútua entre os trabalhadores, de forma que os envolvidos não apenas se preocupassem com a sua própria segurança, mas também com a dos colegas. Com o intuito de tornar o treinamento mais didático e de fácil compreensão, foi desenvolvida uma simulação computacional em 3D para mostrar a ordem de montagem dos lances, o local de posicionamento dos trabalhadores durante a montagem de cada lance específico e onde estavam localizados os cabos guias para fixação dos cintos. A Figura 9 ilustra a simulação desenvolvida, sendo as imagens $\mathrm{A}$ e $\mathrm{B}$ relacionadas com a ordem de montagem dos lances e as demais $(\mathrm{C} \mathrm{a} \mathrm{F})$ com o posicionamento dos trabalhadores e proteções coletivas.

\subsection{Ajustes nos planos após a rodada inicial}

Após o acompanhamento da montagem dos quatro primeiros pavimentos (primeiro dia do trabalho de montagem), foi identificada a necessidade de três ajustes. O primeiro ajuste relacionou-se com o dispositivo metálico, o qual tinha sido projetado inicialmente para transportar a peça na posição do encaixe. Não havia espaço suficiente para descer a peça naquela posição pelo poço da escada. Em função disso, foram realizados ajustes nos cabos de aço para inclinar a peça e permitir a descida sem que houvesse riscos de danos

\section{s planos desenvolvidos objetivavam fazer com que os limites do trabalho seguro, conforme definidos pelos planejadores, fossem visualizados pelos trabalhadores.}

à mesma. Percebeu-se ainda que o dispositivo metálico dificultava a descida, impedindo que os resultados desta medida fossem satisfatórios. Após cálculos de capacidade de carga dos cabos de aço da grua, verificou-se que a escada poderia ser ligada diretamente ao gancho da grua, sem prejuízos às peças. Embora a simulação do processo possa antecipar problemas dessa natureza, isso acabou não acontecendo, visto que não foi considerado que algumas vigas ainda estavam aguardando desfôrma, além de haver desvios nas dimensões da estrutura existente.

O segundo ajuste diz respeito à necessidade de guardacorpo ou fixação de cabos guias nos pavimentos superiores ao local das montagens. A suposição inicial foi de que o

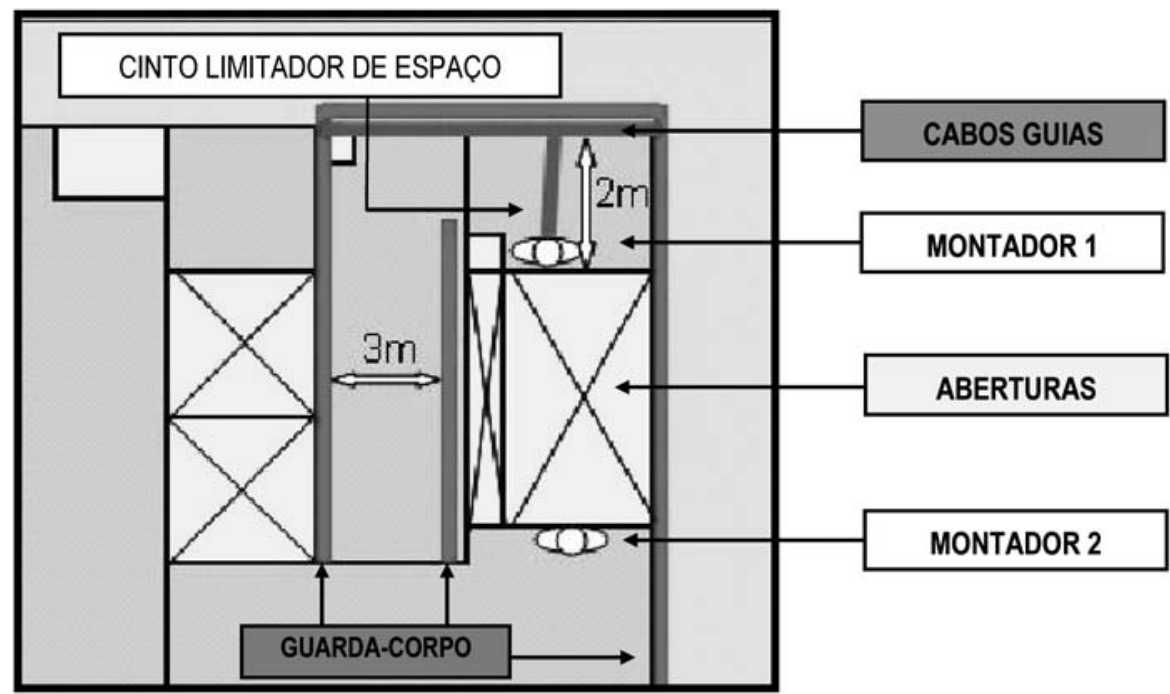

Figura 8: Plano das proteções coletivas no local de montagem das peças. 
sinalizador da grua conseguiria controlar toda a descida das peças permanecendo fixo no último pavimento. Contudo, as peças, durante a descida, eram acompanhadas pelo sinalizador, o qual necessitou se deslocar pelos pavimentos na medida em que os lances desciam, buscando evitar choques acidentais. Em função da não identificação prévia deste fato, em diversos momentos esse profissional esteve em situações perigosas por falta das proteções coletivas. Apesar de o sinalizador estar diariamente no canteiro, o mesmo não foi convidado para participar das discussões realizadas para elaboração dos planos, sendo provável que sua presença nas reuniões pudesse proporcionar a antecipação desse fato.

O último ajuste estava relacionado com a necessidade da fixação de cabos guias no pavimento da montagem. No plano inicial imaginava-se que, para o posicionamento do segundo lance da escada $(200 \mathrm{~kg})$, bastaria que os trabalhadores se posicionassem atrás da viga intermediária. Todavia, durante a montagem decidiu-se que seria mais fácil subir
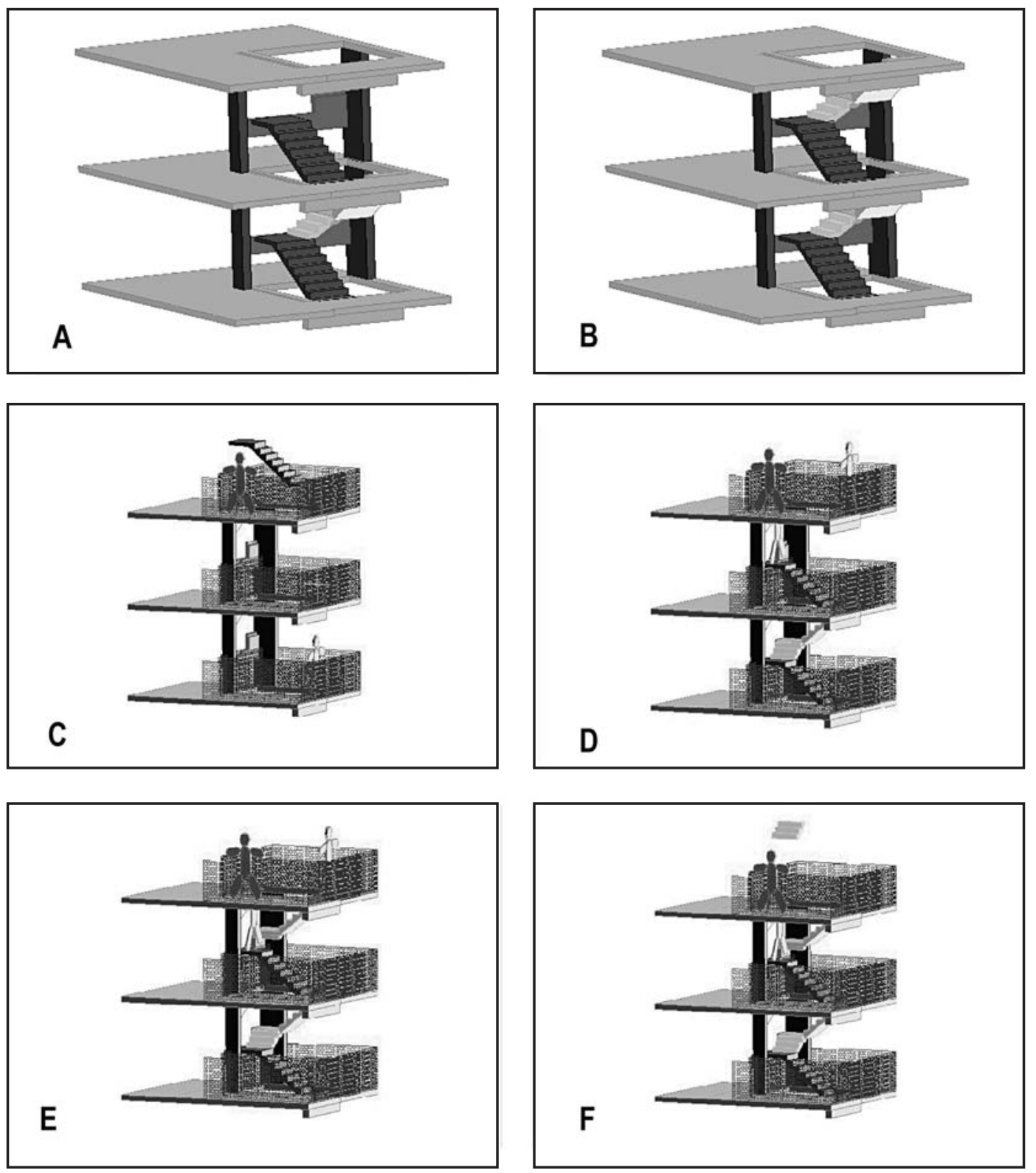

Figura 9: Simulação computacional em 3D desenvolvida para auxiliar no treinamento. 
no primeiro lance já montado para posicionar o segundo, o qual seria o último a ser encaixado. Diante disto, foram definidos os locais para a fixação dos cabos guias também nas laterais do poço.

Algumas medidas poderiam ter sido adotadas para minimizar as necessidades de ajustes no processo estudado. De um lado, os planos poderiam ter sido discutidos com os trabalhadores de forma a obter informações sobre suas ações durante a execução do trabalho e enriquecer o conteúdo do estudo com suas experiências. Isso pode ser feito nas sessões de treinamento, desde que as equipes sejam de fato ativamente envolvidas na discussão do plano. Por outro lado, sempre que possível, podem-se programar visitas em obras que estejam executando processos similares aos estudados para obtenção de informações que tornem os planos ainda mais eficazes.

\section{DISCUSSÃO DO ESTUDO SOB O PONTO DE VISTA DO MODELO DINÂMICO DE GESTÃO DA SEGURANÇA}

Os planos desenvolvidos objetivavam fazer com que os limites do trabalho seguro, conforme definidos pelos planejadores, fossem visualizados pelos trabalhadores. Esses limites foram definidos a partir da identificação de perigos existentes no processo estudado, seja por intermédio da técnica de Análise Preliminar de Perigos (KOLLURU et al., 1996), desenvolvida antes do início do estudo, ou através de uma melhor compreensão ou identificação de novos perigos ao longo do processo de planejamento e ajustes da montagem. Com os planos, a visualização dos limites foi possível por meio da implementação de proteções coletivas e individuais, assim como através da discussão verbal de procedimentos com os funcionários. Além disso, a proposta de colaboração e alerta mútuos sobre os perigos também era uma estratégia para tornar os limites visíveis. Por exemplo, o isolamento da área na qual as peças foram tombadas demarcava o limite para trabalhadores que não estivessem envolvidos e capacitados nessa atividade, visto que estes não poderiam ter acesso a esta região. Entretanto, mesmo que um operador não autorizado entrasse na área isolada, isso não necessariamente implicaria a ocorrência de acidentes, embora esse operador estivesse operando na zona de perigo, visto que estaria infringindo uma boa regra de segurança prevista no planejamento.

Outra proteção física utilizada foi o cinto de segurança com limitador de movimentação frontal para o montador 1 , mostrando que o mesmo estava operando no limite do trabalho seguro (esse limite era fisicamente demarcado pela borda da laje). Este cinto exercia a função de um dispositivo à prova de erros (poka-yoke), na medida em que absorveria possíveis tentativas do montador 1 em avançar demais na direção do poço. Além da proteção contra quedas, esse cinto pode ser 
materiais) em função da inexistência de trabalhadores na parte inferior da escada.

Na medida em que as pressões por eficiência contribuem para deslocar o trabalho para a zona de perda de controle e, principalmente pelo fato de o processo em questão ter sido considerado crítico, foi proposto durante o planejamento que os trabalhadores não fossem submetidos a pressões excessivas quanto a prazos. Desta forma, o prazo final de execução, definido pelos planejadores, permitiu certa folga para a realização do trabalho.

A Figura 10 resume as zonas em que o ambiente de trabalho pode ser dividido e as estratégias de gestão da segurança adotadas em cada uma delas.

\section{CONCLUSÕES}

O processo de planejamento de processos críticos, discutido neste artigo, serve como um recurso que complementa outras iniciativas que buscam reduzir a incidência de acidentes do trabalho na indústria da construção. Sua contribuição está embasada na premissa de que o projeto dos processos pode reduzir a probabilidade de ocorrência de erros humanos, os quais normalmente são combatidos apenas por meio de iniciativas tradicionais de treinamento e motivação da mão-de-obra. Além disso, este estudo demonstra como podem ser aplicados na prática da construção civil os conceitos de zonas de trabalho seguras e inseguras, limites de desempenhos e suas estratégias de gestão, conforme a proposta do modelo dinâmico de gestão de segurança.

O planejamento dos processos críticos pode ser realizado segundo três etapas: (a) coleta de informações e decisões iniciais; (b) preparação e difusão dos planos; e (c) ajustes após a rodada inicial. $\mathrm{Na}$ fase inicial, as informações podem ser buscadas em quatro principais fontes: interação com os fornecedores; visitas aos locais de execução do processo; visitas em canteiros que estiverem executando processos similares; e conversa com funcionários que provavelmente participarão da execução, desde que tenham experiência prévia. No caso deste estudo, foram realizadas reuniões com o fornecedor e visitas aos locais de montagem. A ausência do envolvimento dos montadores constituiu-se em um forte fator gerador de falhas durante a montagem da escada. Em relação à segunda etapa, propõe-se a elaboração de dois planos de proteções coletivas. O primeiro deles refere-se às proteções em nível do canteiro de obras. O segundo estabelece as proteções necessárias no local das montagens. Deve ser preparado também um plano de treinamento a ser reali-

\begin{tabular}{|c|c|c|}
\hline Zona & $\begin{array}{l}\text { Estratégias de gestão da } \\
\text { segurança }\end{array}$ & Ações práticas \\
\hline \multirow[t]{4}{*}{ Segurança } & \multirow{4}{*}{$\begin{array}{l}\text { Ampliar esse espaço por } \\
\text { meio de planejamento e } \\
\text { controle }\end{array}$} & $\begin{array}{l}\text { Programação junto ao fornecedor da entrega de peças específicas para um dia de } \\
\text { montagem, evitando estoques no canteiro e criação de novos perigos. }\end{array}$ \\
\hline & & $\begin{array}{l}\text { Planejamento do local de posicionamento dos caminhões, de modo a fazer com que as } \\
\text { peças içadas percorressem a menor distância possível até o local de montagem. }\end{array}$ \\
\hline & & $\begin{array}{l}\text { Consideração, durante a elaboração dos planos, das condições climáticas e da capacidade } \\
\text { de carga do equipamento de transporte das peças. }\end{array}$ \\
\hline & & $\begin{array}{l}\text { Acompanhamento das primeiras montagens para ajustes nos planos. Esse monitoramento } \\
\text { serviu para retro-alimentar planejamento. }\end{array}$ \\
\hline \multirow[t]{2}{*}{ Perigo } & $\begin{array}{l}\text { Dar visibilidade ao limite } \\
\text { de trabalho seguro }\end{array}$ & $\begin{array}{l}\text { Explicitação em planos específicos e implementação das proteções coletivas definidas. Por } \\
\text { exemplo, definição e isolamento da área para o tombamento das peças. }\end{array}$ \\
\hline & $\begin{array}{l}\text { Capacitar para } \\
\text { reconhecimento dos } \\
\text { limites }\end{array}$ & $\begin{array}{l}\text { Treinamento visando orientar quanto à necessidade de responsabilidade coletiva perante } \\
\text { as montagens e respeito às proteções, sejam coletivas ou individuais, conforme traçado nos } \\
\text { planos. }\end{array}$ \\
\hline \multirow[t]{2}{*}{$\begin{array}{l}\text { Perda de } \\
\text { controle }\end{array}$} & \multirow{2}{*}{$\begin{array}{l}\text { Projetar maneiras para } \\
\text { limitar as conseqüências } \\
\text { do perigo em caso de } \\
\text { perda de controle }\end{array}$} & $\begin{array}{l}\text { Definição e isolamento da área no fundo do poço para minimizar efeitos negativos em caso } \\
\text { de perda de controle. }\end{array}$ \\
\hline & & $\begin{array}{l}\text { Trabalho na borda da laje com utilização de um cinto que limitava o deslocamento de um } \\
\text { dos montadores e atuava como lembrete dessa condição (dispositivo poka-yoke). }\end{array}$ \\
\hline
\end{tabular}

Figura 10: Resumo das ações preventivas e as respectivas estratégias de gestão da segurança. 
zado antes do início das montagens. No estudo realizado, os planos das proteções coletivas contribuíram principalmente para explicitar os limites de trabalho seguro por intermédio de aparatos físicos.

O plano de treinamento contribuiu para explicitar limites através da comunicação verbal, utilizando-se simulação virtual visando à melhor compreensão do processo de montagem, especialmente pelos trabalhadores. Quanto à simulação realizada, foram identificadas algumas limitações após o primeiro ciclo de montagens como, por exemplo, a não consideração da possibilidade de descida com as fôrmas das vigas ainda no local.

O exemplo mencionado diz respeito à não consideração de aspectos da dinâmica da obra. Uma vez que existem técnicas de simulação que permitem fazer isto, propõe-se que em estudos futuros seja considerada essa questão. A terceira etapa busca identificar necessidades de ajustes nos planos após a execução do primeiro ciclo de montagens, com o intuito de proporcionar melhorias para os ciclos de montagem seguintes.

Quanto ao desenvolvimento de estudos futuros, foram identificadas algumas lacunas que podem ser investigadas com o intuito de melhorias no planejamento e controle da segurança de processos críticos. Embora este estudo tenha focado o processo de montagem da escada a partir de um produto definido, não foi objeto desta pesquisa estudar o produto em si e a tecnologia intrínseca ao mesmo desde sua concepção

\title{
A lém disso, este estudo demonstra como podem ser aplicados na prática da construção civil os conceitos de zonas de trabalho seguras e inseguras, limites de desempenhos e suas estratégias de gestão, conforme a proposta do modelo dinâmico de gestão de segurança.
}

\begin{abstract}
e projeto. Algumas decisões de concepção e projeto podem garantir uma maior segurança durante a etapa de execução. Uma outra oportunidade de melhorias nos procedimentos adotados neste estudo, diz respeito à incorporação de mecanismos formais de avaliação de desempenho, principalmente por meio de indicadores. Além disto, a participação de todos os envolvidos no processo, em particular dos trabalhadores, pode representar ganhos significativos no desempenho dos planos, na medida em que o processo de construção não é de todo conhecido pelos planejadores.
\end{abstract}

\section{Artigo recebido em 08/08/2006 Aprovado para publicação em 06/05/2008}

\section{REFERÊNCIAS}

BALLARD, G. The Last Planner System of Production Control. 2000. 192 f. PhD Thesis (Doctor of Philosophy) - School of Civil Engineering, University of Birmingham, Birmingham, UK, 2000.

BALLARD, G.; HOWELL, G. Implementing Lean Construction: improving downstream performance. In: ALARCON, L. (Ed.). Lean Construction. Rotterdam: A. A. Balkema, p. 111-125, 1997.

CAMBRAIA, F. B. Gestão integrada entre segurança e produção: aperfeiçoamentos em um modelo de planejamento e controle. 2004. 174 f. Dissertação (Mestrado em Engenharia Civil) Programa de Pós-Graduação em Engenharia Civil, Universidade Federal do Rio Grande do Sul, Porto Alegre, 2004.

CIRIBINI, A.; RIGAMONTI, G. Time/ Space Chart Drawings Techniques for the Safety Management. In: INTERNACIONAL CONFERENCE OF CIB WORKING COMISSION W99, 2., 1999, Hawaii. Proceedings. Rotterdam: A. A. Balkema, p. 25-32, 1999.

COStella, M. Análise dos Acidentes do Trabalho e Doenças Ocupacionais Ocorridos na Atividade de Construção Civil no Rio Grande do
Sul em 1996 e 1997. 1999. 168 f. Dissertação (Mestrado em Engenharia Civil) - Programa de Pós-Graduação em Engenharia Civil, Universidade Federal do Rio Grande do Sul, Porto Alegre, 1999.

DIAS, L. M.; FONSECA, M. S. Plano de Segurança e de Saúde na Construção. Lisboa: Instituto de Desenvolvimento e Inspeção das Condições de Trabalho, 1996.

HINZE, J. Construction planning and scheduling. Upper saddler river, NJ: Prentice-Hall, 326 p., 1998. 


\section{REFERÊNCIAS}

HINZE, J. Making Zero Injuries a Reality. A report to the Construction Industry Institute, University of Florida, Gainesville (Report 160), 2002.

HOWELL, G. A. et al. Working Near the Edge: a new approach to construction safety. In: ANNUAL CONFERENCE ON LEAN CONSTRUCTION, 10., 2002, Gramado. Proceedings. Porto Alegre: UFRGS, p. 49-60, 2002.

KARTAN, N. Integrating Safety and Health Performance Into Construction CPM. Journal of Construction Engineering and Management, New York, v. 121, n. 4, p. 121-126, 1997.

KOLLURU, R.; BARTELL, S.; PITBLADO, R.; STRICOFF, R. Risk Assessment and Management Handbook. New York: MacGraw-Hill, 1996.

LAUFER, A.; TUCKER, R. L. Competence and Timing Dilemma in Construction Planning. Construction Management and Economics, London, v. 6, n. 6, p. 339-355, 1988.
LAUFER, A.; TUCKER, R.L. Is Construction Planning Really Doing its Job? a critical examination of focus, role and process. Construction Management and Economics, London, v. 5, n. 5, p. 243-266, 1987.

MACCOLLUM, D. Construction Safety Planning New York: Van Nostrand Reinhold, 285 p., 1995.

RASMUSSEN, J. Risk Management in a Dynamic Society: a modeling problem. Safety Science, Amsterdam, v. 27, n. 2/3, p. 183-213, 1997.

RASMUSSEN, J.; PEJTERSEN, A. M.; GOODESTEIN, L. P. Cognitive Systems Engineering. New York: John Wiley e Sons, 378 p., 1994.

REASON, J. Managing the Risks of Organizational Accidents. Burlington: Ashgate, 1997.

SAURIN, T. A. Segurança e Produção: um modelo para o planejamento e controle integrado. 2002. Tese (Doutorado em Engenharia de
Produção) - Programa de Pós-Graduação em Engenharia de Produção, Universidade Federal do Rio Grande do Sul, Porto Alegre, 2002.

SAURIN, T. A.; FORMOSO, C. T.; GUIMARÃES, L. B. M. Safety and production: an integrated planning and control model. Construction Management and Economics, London, v. 22, n. 2, p. 159-169, 2004.

SLACK, N. et al. Administração da Produção. São Paulo: Atlas, 1997.

SURAJI, A.; DUFF, R.; PECKITT, S. Development of Causal Model of Construction Accident Causation. Journal of Construction Engineering and Management, London, v. 127, n. 4, p. 337344, 2001.

TRANI, M. L.; LANTICINA, M. Safety Oriented Time Scheduling on the Construction Site. In: INTERNACIONAL CONFERENCE OF CIB WORKING COMISSION W99, 2003, São Paulo. Anais eletrônicos. CD-ROM. São Paulo: USP, 2003.

\section{SOBRE OS AUTORES}

\section{Fabrício Borges Cambraia}

Núcleo Orientado para a Inovação das Edificações

Universidade Federal do Rio Grande do Sul.

End.: Av. Osvaldo Aranha, 99, $3^{\circ}$ andar - Porto Alegre - RS - Brasil - CEP 90040-020

Fax: 55 (51) 3316-4054.

E-mail: fabricio@ppgec.ufrgs.br

\section{Tarcísio Abreu Saurin}

Laboratório de Otimização de Produtos e Processos

Universidade Federal do Rio Grande do Sul.

End.: Praça Argentina, $n^{\circ} 9,2^{\circ}$ andar - Porto Alegre - RS - Brasil - CEP 90040-020

Fax: 55 (51) 3316-4007.

E-mail: saurin@ufrgs.br

\section{Carlos Torres Formoso}

Núcleo Orientado para a Inovação das Edificações,

Universidade Federal do Rio Grande do Sul.

End.: Av. Osvaldo Aranha, 99, $3^{\circ}$ andar - Porto Alegre - RS - Brasil - CEP 90040-020

Fax: 55 (51) 3316-4054.

E-mail: formoso@ufrgs.br 